\title{
Linguagem Cidadã de Processos em Sistemas Digitais
}

\author{
Citizen Process Language in Digital Systems
}

\author{
CARVALHO, Luiz Paulo \\ UFRJ, Doutorando \\ luiz.paulo.carvalho@ppgi.ufrj.br
}

\author{
CAPPELLI, Claudia \\ UFRJ, Pesquisadora \\ claudia.cappelli@gmail.com
}

\section{RESUMO}

O entendimento de informações é um requisito de qualidade premente para transparência, necessário às bases de uma sociedade engajada e participativa, democrática. O governo determina o uso de Tecnologias da Informação, como a Internet, para que a Transparência, ativa e passiva, seja habilitada e garanta às partes interessadas, como o cidadão, o maior alcance possível dos dados públicos e dos dados abertos. Diversos são os desafios associados com o ato de transparecer informações, entre eles está o de comunicar efetivamente informações processuais públicas aos usuários, como manda a legislação. Há como utilizar elementos gráficos e textuais combinados de forma simples, clara e objetiva para construir uma comunicação entendível entre as partes? Se modelos de processos, construídos a partir de notações técnicas como BPMN, são de difícil compreensão, como transparecer essas informações processuais? Com fundamentações em Design, Comunicação Visual e Sistemas de Informação, apresentamos o uso de Linguagem Cidadã como parte da solução destes desafios por uma linguagem cidadã de processos, chamada GERAL, direcionada ao amplo entendimento pelo cidadão.

Linguagem Cidadã, Transparência, Processo de Negócio, Sistema de Informação, Design

\begin{abstract}
Understanding information is a pressing quality need for transparency, which is necessary for the foundations of an engaged, participatory, democratic society. The government mandates the use of Information Technologies, such as the Internet, so that active and passive transparency is enabled and ensures that stakeholders, such as citizens, have the widest possible range of public and open data. There are several challenges associated with the act of information disclosure, including communicating public procedural information to users, as required by law. Is it possible to use simple, clear and intuitive combined graphic and textual elements to build understandable communication between parts? If process models built on technical notations such as BPMN, are difficult to understand, how to disclose this information? Based on Design, Visual Communication and Information Systems, we present the use of Citizen Language as part of the solution of these challenges by a citizen process language, called GERAL, directed to the broad understandability by citizens.
\end{abstract}

Citizen Language, Transparency, Business Process, Information System, Design 




$17^{\circ}$ ERGODESIGN \& USIHC 2019

PUC-Rio, 11 a 13 de dezembro

Rio de Janeiro, RJ, Brasil $17^{\circ}$ Ergodesign - Congresso Internacional de Ergonomia e Usabilidade de Interfaces Humano Tecnológica: Produto, Informações Ambientes Construídos e Transporte

$17^{\circ}$ USIHC - Congresso Internacional de Ergonomia e Usabilidade de Interfaces Humano Computador

\section{INTRODUÇÃO}

A crescente demanda por verdades baseadas na transparência tem aumentado no contexto das transformações globais. A importância da abertura do fluxo de informações está criando uma sociedade aberta com objetivo de estabelecer uma sociedade democrática e cidadãos engajados, capazes de entender e acessar a informação disponível (HOLZNER E HOLZNER, 2006).

A Estratégia de Governança Digital (EGD), pelo objetivo estratégico de promoção da transparência por meio de Tecnologias de Informação e Comunicação (TIC), determina a ampliação do fornecimento de informações mais claras e simples ao cidadão (BRASIL, 2018a).

Legislações brasileiras determinam a transparência de dados e informações públicos, como a lei no 12.527 (BRASIL, 2011), Lei de Acesso à Informação (LAI); e lei no 13.460 (BRASIL, 2017), que anuncia a Carta de Serviços ao Usuário (CSU). Cada órgão ou entidade pública deve transparecer sua CSU em sítio eletrônico do órgão ou entidade na internet, trazendo informações claras e precisas em relação a cada um dos serviços prestados pelo mesmo, utilizando linguagem simples e entendível (BRASIL, 2017). Serviços e produtos públicos são prestados através de processos de negócio (DUMAS et al., 2018).

Outras categorias de dados e informações estão recebendo maior importância em seus requisitos de entendimento, para além da divulgação. Por exemplo:

(i) Transparência algorítmica, como operam e o que tratam as plataformas digitais (KOENE et al., 2019), como Facebook. A lei no 13.709 (BRASIL, 2018b), Lei Geral de Proteção de Dados Pessoais (LGPD), busca resolver ou amenizar as influências negativas que algoritmos, a partir dos nossos dados pessoais, estão gerando na sociedade, não apenas nos indivíduos ou na coletividade, como também na Democracia como tradicionalmente conhecemos hoje (MAGRANI, 2019).

(ii) Transparência de termos e condições em serviços digitais (BUTTARELLI, 2019), abstendo da realidade de que alguns destes objetos podem ter um tempo estimado de leitura integral de mais de vinte e quatro horas, alguns indicavam textos absurdos, como relacionados à produção de armamento nuclear; reanimação de cadáveres; ou cessão da sua "alma imortal" ao prestador do serviço (STEGNER, 2018).

(iii) Transparência na distribuição de processos públicos (ROVER, 2014), onde há opacidade total do procedimento de como são atribuídos os processos judiciais eletrônicos aos respectivos juízes.

(iv) Transparência no processo eleitoral brasileiro (MEIRA, 2015). As urnas funcionam como caixas-pretas. Apesar de, idealisticamente, sabermos como se dá o processo eleitoral, é impossível auditar o processo de captura das intenções de voto do eleitor. A possibilidade de um sistema ser auditado é um requisito para que a transparência seja habilitada (CAPPELLI, 2009).

Cappelli (2009) constrói um grafo de interdependência representando a Transparência Organizacional, através de níveis de características, ilustrado na Figura 1.

Comum a todos os casos estão as deficiências e desafios associados à transparência processual. Incluído o entendimento, este deve respeitar princípios democráticos e legais associado ao público-alvo interessado, seus usuários. 
$17^{\circ}$ ERGODESIGN \& USIHC 2019

PUC-Rio, 11 a 13 de dezembro

Rio de Janeiro, RJ, Brasil $17^{\circ}$ Ergodesign - Congresso Internacional de Ergonomia e Usabilidade de Interfaces Humano Tecnológica: Produto, Informações Ambientes Construídos e Transporte

$17^{\circ}$ USIHC - Congresso Internacional de Ergonomia e Usabilidade

de Interfaces Humano Computador

Figura 1: Grafo de interdependências que compõe a Transparência (CAPPELLI, 2009)



A aplicação de transparência em Sistemas de Informação (SI) é uma nova e importante preocupação ao projetar um software que automatiza a prestação dos serviços, processa informações e interage com pessoas (CAPPELLI E LEITE, 2010). TIC auxiliam a definir, implementar, medir, verificar, estabelecer e garantir a operacionalização da transparência e de seus requisitos.

\subsection{Linguagem Cidadã}

Com enfoque na qualidade do entendimento, um tópico que tem atraído interesse e atenção é a Linguagem Cidadã ${ }^{1}$, definida pela Controladoria Geral da União (CGU) como:

"É aquela clara, concisa, objetiva, desburocratizada. Mais do que isso, é aquela que atenta para o contexto sociocultural da pessoa a que é dirigida, adaptando-se às suas necessidades. Assim, se mostra inadmissível, em tese, utilizar-se de linguagem técnica ou que requeira estudos ou investigações posteriores para sua correta compreensão. No entanto, se o cidadão a que se destina a resposta da ouvidoria seja reconhecidamente um especialista em uma área específica, não haverá problemas em utilizar linguagem mais técnica." (Controladoria Geral da União, 2015)

Em 2016 foi lançado "'Fugindo do 'burocratês': como facilitar o acesso do cidadão ao serviço público. Dicas de Como Comunicar um Serviço Público para o seu Público-Alvo Utilizando Linguagem Cidadã" (BRASIL, 2016) com operacionalizações para construção ou tradução de textos "burocratizados" para textos habilitados em Linguagem Cidadã.

1 Linguagem Cidadã é o termo brasileiro adotado oficialmente pelo governo federal, como sinônimo podemos encontrar os termos Linguagem Clara (Clear Language) ou Plain Language, sem tradução equivalente ao português. 
Para democracia informacional, Linguagem Cidadã é mais do que um tópico em Comunicação, é também um problema de Direitos Humanos (MOWAT, 2004); simultaneamente no serviço público agrega os valores de eficiência, transparência e confiança (FRANZONI, 2009).

No México, após a implantação de iniciativas governamentais de operacionalização dos fundamentos da Linguagem Cidadã houve significativa redução nas questões e dúvidas em relação às informações públicas e diminuição do tempo de leitura delas. De três milhões e quatrocentos mil leitores, dúvidas diminuíram de dezoito mil seiscentas e noventa e três (18.693) para quatro mil seiscentas e noventa e quatro (4.694) e o tempo de leitura, em minutos, de quatro mil trezentos e oitenta e um (4.381) para dois mil e trezentos (2.300) (FRANZONI, 2009).

Além do Brasil, várias comunidades, sejam governamentais ou de interesse privado, possuem seus materiais de Linguagem Cidadã, como México (MÉXICO, 2004); Colômbia (COLÔMBIA, 2015); Estados Unidos (PLAIN, 2011); União Europeia (UE, 2010), dentre outras. Apesar da extensa quantidade de material, há uma carência de aprofundamento epistemologicamente fundamentado sobre transparência de processos, sendo a esmagadora maioria voltada para transparência de informações textuais.

Quando os guias de Linguagem Cidadã se referem à divulgação de processos entendíveis ocorre um reducionismo de soluções para uso de listas ou fluxogramas simplórios sem explicações complementares de como apresentar a informação nos mesmos. Listas, parecidas com a sintaxe de Casos de Uso, são formatos recomendáveis para processos com quantidade limitada de informações (OTTENSOOSER et al., 2012) e que não necessitem de dados de apoio. Considerando a escalabilidade, listas podem se tornar tão extensas ou complexas de ler quanto texto corrido em linguagem natural.

Em vista de resolver este problema, uma solução proposta foi construir uma linguagem cidadã de processos para transparência de informações processuais, voltada a sistemas digitais. $E$, como indica a nomenclatura, utilizando os princípios e recomendações de Linguagem Cidadã.

\section{UMA LINGUAGEM CIDADÃ PARA PROCESSOS}

Surgiu em nós o interesse sobre a transparência de processos durante um projeto em 2013, dedicado à modelagem dos processos de negócio de atendimento aos alunos pela secretaria do curso de SI da Universidade Federal do Estado do Rio de Janeiro (UNIRIO). Após modelarmos todos os devidos processos, surgiu um problema: os artefatos construídos utilizando a notação Business Process Model and Notation (BPMN) não apresentam boa compreensibilidade (GENON et al., 2011), sendo demasiado complexos para serem transparecidos.

Utilizando um catálogo contendo características, operacionalizações e mecanismos para melhorar o entendimento de processos públicos (ENGIEL, 2012) construímos uma notação simplificada e facilitada para comunicar as informações processuais ao público-alvo (CARVALHO et al., 2016), os alunos. As figuras 2 e 3 expõe um modelo em BPMN e em linguagem cidadã. 
$17^{\circ}$ ERGODESIGN \& USIHC 2019

PUC-Rio, 11 a 13 de dezembro

Rio de Janeiro, RJ, Brasil $17^{\circ}$ Ergodesign - Congresso Internacional de Ergonomia e Usabilidade de Interfaces Humano Tecnológica: Produto, Informações Ambientes Construídos e Transporte

$17^{\circ}$ USIHC - Congresso Internacional de Ergonomia e Usabilidade de Interfaces Humano Computador

Figura 2: Processo de Quebra de Pré-requisitos em BPMN (CARVALHO et al., 2016)

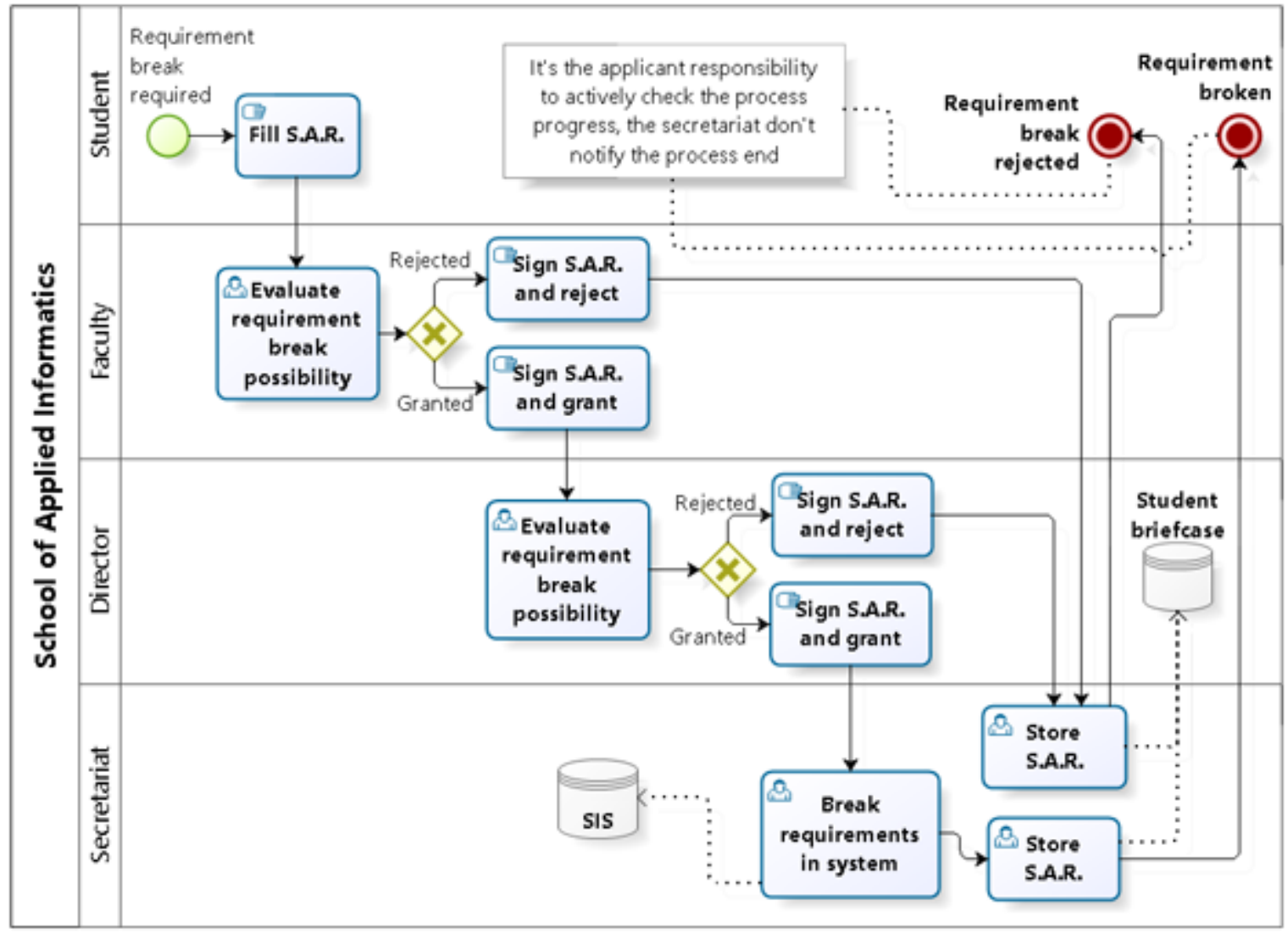

Figura 3: Processo de Quebra de Pré-requisitos em uma linguagem cidadã (CARVALHO et al., 2016)



Neste primeiro momento não tínhamos fundamentação em Linguagem Cidadã, então tomamos decisões baseadas em requisitos de simplicidade, intuitividade e amigabilidade (CAPPELLI, 2009) por: (i) indicação do catálogo de Engiel (2012), com base fundamentada em qualidade de entendimento de modelos de processos de negócios; (ii) senso comum, como utilizar comunicação informal; reduzir ao máximo as informações necessárias; utilizar tamanho de fonte legível ao público-alvo; ser assertivo; dentre outros. 
$17^{\circ}$ ERGODESIGN \& USIHC 2019

PUC-Rio, 11 a 13 de dezembro

Rio de Janeiro, RJ, Brasil $17^{\circ}$ Ergodesign - Congresso Internacional de Ergonomia e Usabilidade de Interfaces Humano Tecnológica: Produto, Informações Ambientes Construídos e Transporte

$17^{\circ}$ USIHC - Congresso Internacional de Ergonomia e Usabilidade de Interfaces Humano Computador

O sistema online CAMELoT (OLIVEIRA, 2018) foi construído oferecendo uma tradução semiautomática entre BPMN e esta linguagem cidadã. Sua interface, como sua instrução de uso, foi construída respeitando princípios de Linguagem Cidadã.

Figura 4: Instrução de uso do CAMELoT, utilizando Linguagem Cidadã



Exporte o seu modelo de Processos em BPMN para $X P D L$. Somente com esse padrão de arquivo todo o seu processo será conhecido pela ferramenta.
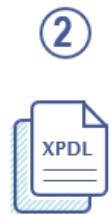

Selecionar um arquivo XPDL no seu

dispositivo e o sistema realizará o primeiro passo da adaptação internamente.
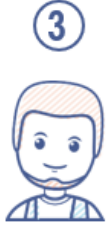

Na tela de configuração você adapta o processo de negócio como preferir para esta linguagem cidadã.
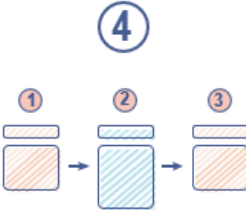

O sistema mostrará o modelo final em linguagem cidadã Na tela de exposição e você poderá salvar como imagem ou reiniciar a adaptação.

Para validar o entendimento realizamos uma pesquisa para mensurá-lo (CARVALHO et al., 2015), onde obtivemos as seguintes conclusões:

- Para um público-alvo com antecedentes instrucionais de letramento gráfico de diagramas, como os próprios alunos de SI em períodos mais avançados, os modelos de BPMN apresentaram indicadores de entendimento satisfatórios; usuários sem estes antecedentes apresentaram baixo indicador de entendimento para BPMN e altos para linguagem cidadã;

- Expondo apenas a sintaxe, sem conteúdo semântico, a linguagem cidadã teve o pior indicador de entendimento. Significando que: (i) os participantes não conseguiram associar apenas a "carcaça" da notação da Figura 3 com nenhuma bagagem gráfica conhecida anteriormente; (ii) a qualidade do modelo nesta linguagem cidadã está fortemente associado com seu conteúdo semântico;

- Um dos participantes, cursando Design Industrial, recomendou maior requinte na fundamentação de comunicação visual, formas, cores e desenhos.

Esta linguagem cidadã despertou um interesse de uso de outras comunidades, com objetivo de transparecer seus processos. Surgiu um novo problema, a dependência de especialistas para 0 uso dessa linguagem cidadã. Os atores dessas comunidades nos pediam auxílio e apoio de trabalho para utilizá-la, sendo que a intenção era que o uso dela fosse autônomo e independente.

Observando a falta de fundamentação epistemológica fundamentada, como observado pelo participante de Design Industrial, e a deficiência na autonomia e independência de sua instrumentalização, surgiu um novo desafio: habilitar o uso de uma linguagem cidadã fundamentada com propriedade com o máximo de autonomia e independência possível por interessados leigos em modelagem de processos de negócios.

\section{GERAL E O GUIA BPMN PRA GERAL}

Desenvolvemos uma linguagem cidadã para processos epistemologicamente fundamentada, chamada GERAL (CARVALHO, 2019). O foco desse trabalho será expor apontamentos baseados em Linguagem Cidadã que alicerçaram sua construção. 
A GERAL é a notação, o objeto mais relevante, que compõe um framework conceitual de tradução entre BPMN e GERAL, composto de meta-modelo, notação, ferramental e método.

\subsection{Meta-modelo}

O meta-modelo é, em breve explicação, um modelo que instrui como construir modelos (WESKE, 2012), a partir de elementos como uma sintaxe, que é um conjunto de regras de formação.

Sendo dedicado à tradução utilizando BPMN como insumo, presamos pela preservação da intuitividade dos elementos entre a BPMN e a GERAL, o que Clark et al. (2015) denominam como mapeamento. Considerado o mapeamento, importamos o máximo de elementos plausíveis da BPMN para GERAL, aproveitando suas vantagens em representação de processos e omitindo elementos complexos à transparência.

Figura 5: Meta-modelo da GERAL (CARVALHO, 2019)

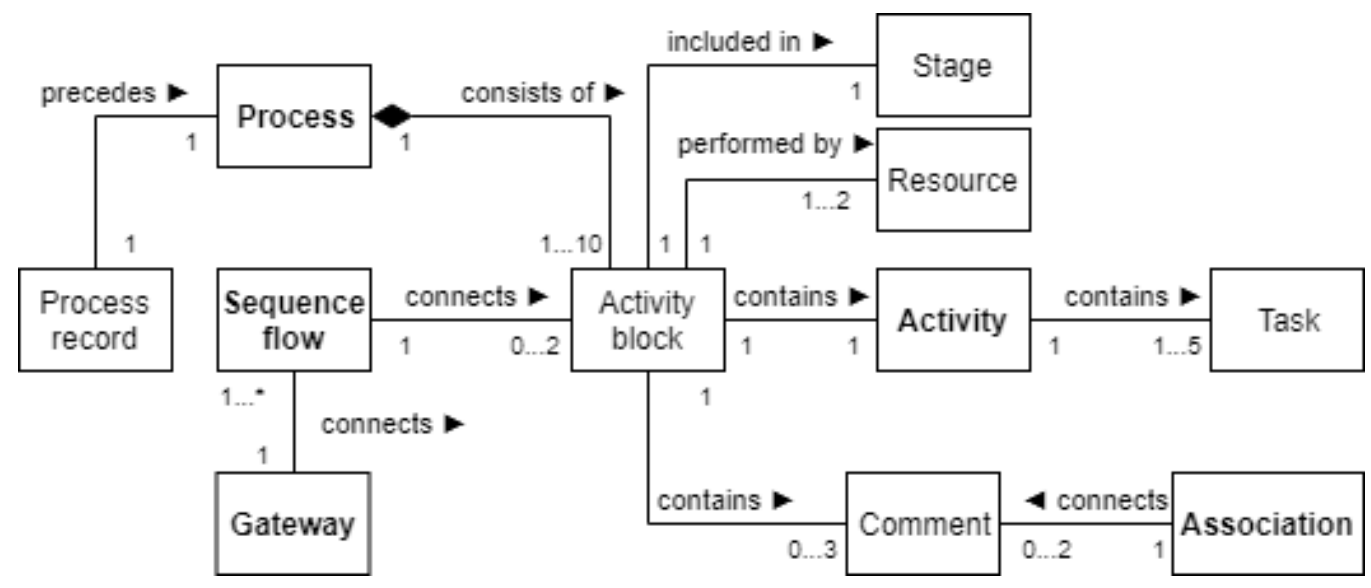

A Figura 5 expõe o meta-modelo conceitual, os elementos grifados (Process, Sequence flow, Gateway, Activity e Association) são importados exatamente com mesmo significado que BPMN. Um usuário habituado com a interpretação de modelos de processos BPMN, ou similares, terá uma curva de aprendizado mais amena ao se deparar com um modelo GERAL.

Figura 6: Cores seguras permitidas pela GERAL
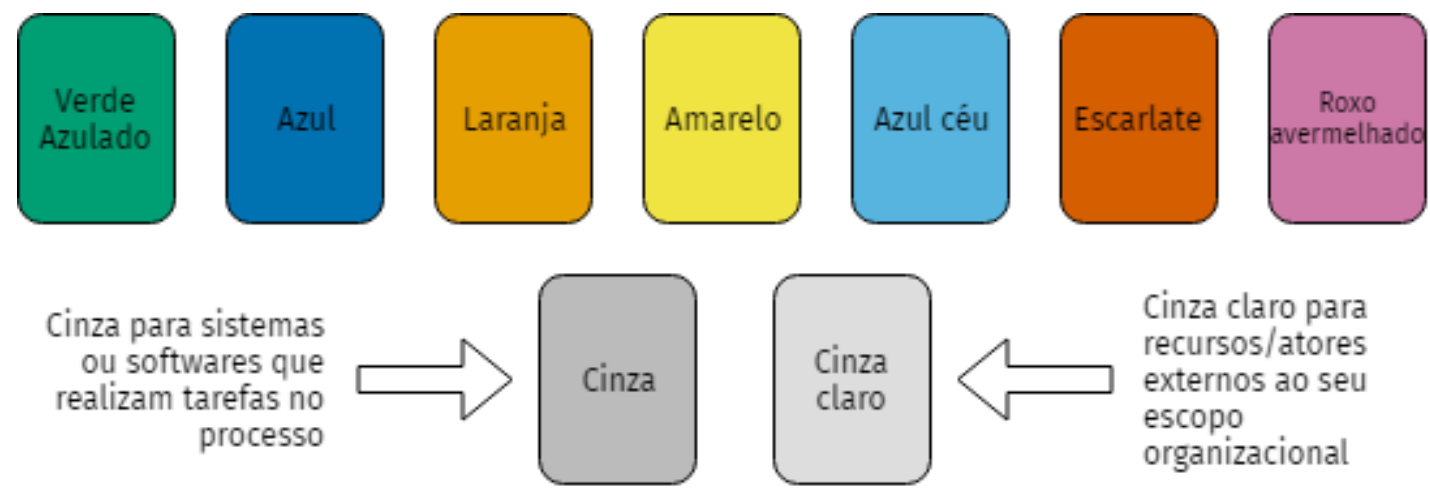

Para sintaxe foram incorporadas regras de construção para não delegar ao modelador a liberdade de tomar decisões equivocadas para uma comunicação simples, clara, amigável e objetiva. A qualidade dos possíveis artefatos gerados por uma notação é inerente a suas regras (KROGSTIE, 
2016). Por exemplo, em BPMN o uso de cores é de livre escolha do modelador, na GERAL há uma limitação de cores permitidas, um dos motivos está no respeito à acessibilidade da pessoa daltônica (CARVALHO et al., 2018). A Figura 6 expõe cores seguras permitidas pela GERAL.

$\mathrm{Na}$ Semântica, além dos conceitos importados da BPMN, recuperamos informações da perspectiva de dados necessários para que o usuário realize o processo e que não são representados em BPMN, como endereço do local ou detalhes de equipamentos ou materiais essenciais, como valores. A boa prática de BPMN recomenda que estas informações fiquem em um documento complementar e completo do processo (DUMAS et al., 2018), só que alguns destes dados são essenciais ao efetivo cumprimento do processo, a comunicação deve ser informal e instrucional, não limitada por regras de conteúdo.

\subsection{Ferramental}

Duas ferramentas computacionais são recomendadas, CAMELoT (OLIVEIRA, 2018) e draw.io ${ }^{2}$. CAMELoT já foi apresentada anteriormente neste trabalho.

A ferramenta draw.io foi selecionada pela sua simplicidade e clareza, um ambiente de diagramação livre, sem limitações de sintaxe notacional. Possui poucas e objetivas funcionalidades, ideais ao escopo desejado de construir modelos diagramáticos simples.

O Estudo de Caso (YIN, 2018) da pesquisa de validação e avaliação onde foi utilizado o draw.io expôs níveis diferentes de resposta em questão de entendimento no uso da ferramenta. Desde participantes declarando que a ferramenta é muito fácil e simples de usar, como o contrário (CARVALHO, 2019). Todas as participantes da pesquisa, apesar das dificuldades, conseguiram construir os modelos GERAL utilizando a draw.io. O que variou foi a curva de aprendizagem pelo tempo, a tarefa de diagramar, por si só, é complexa para usuários não habituados.

\subsection{Notação}

A notação, GERAL propriamente dita, foi o componente do framework com maior enfoque. Sendo uma representação gráfica, seguimos a percepção de que os elementos notacionais gráficos influenciam diretamente a sua comunicabilidade (KROGSTIE, 2016; ENGELHARDT, 2002; MOODY, 2009), consequentemente sua transparência.

A partir de uma análise morfossintática gráfica (ENGELHARDT, 2002) dos elementos da BPMN, observa-se que a composição de alguns elementos possui muitos níveis de informação aninhados.

Figura 7: Análise morfossintática de um elemento gráfico da BPMN

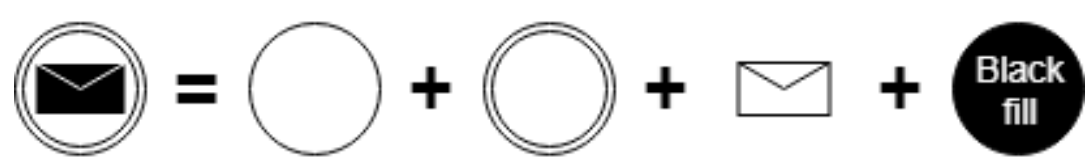

Na Figura 7 uma análise morfossintática é exposta, o elemento possui quatro camadas de informações necessárias para sua interpretação completa, cada um destes elementos também possui suas regras e dados implícitos, por exemplo, o ícone de carta não está limitado ao significado de "mensagem" ou, literalmente, "carta", sim de qualquer material enviado, como um

\footnotetext{
2 Draw.io
} 




\section{$17^{\circ}$ ERGODESIGN \& USIHC 2019 \\ PUC-Rio, 11 a 13 de dezembro \\ Rio de Janeiro, RJ, Brasil}

$17^{\circ}$ Ergodesign - Congresso Internacional de Ergonomia e Usabilidade de Interfaces Humano Tecnológica: Produto, Informações Ambientes Construídos e Transporte

$17^{\circ}$ USIHC - Congresso Internacional de Ergonomia e Usabilidade

de Interfaces Humano Computador

pacote ou uma encomenda. Um evento intermediário de envio de mensagem é composto de: forma circular significando evento; contorno em linha dupla simples significando que o evento é intermediário; o ícone de carta significa que é o trâmite de uma "mensagem"; o preenchimento do ícone em preto significa que é um evento de envio.

A GERAL utiliza elementos gráficos como contêineres, porque ícones e elementos gráficos podem ser interpretados de maneiras diferentes, em contextos diferentes, por públicos diferentes. Desta forma optamos por "sacrificar" os elementos notacionais gráficos de representação conceitual e utilizar apenas elementos textuais.

A BPMN em sua versão mais atual, 2.0.2, possui cento e dezesseis (116) elementos notacionais, excluídas combinações. A GERAL tem sete (7), apresentando uma menor sobrecarga cognitiva (MOODY, 2009) na apreensão à curto prazo, que é a nossa intenção, já que o usuário não espera primeiro aprender uma notação nova para, só depois, entender o processo com qualidade.

Ao optarmos em atribuir maior importância aos requisitos associados ao entendimento, como simplicidade, amigabilidade, intuitividade, dentre outros, simultaneamente cedemos em outros requisitos qualitativos, negociamos vantagens e desvantagens. Não há como representar todos os elementos da realidade em um único artefato comunicacional, através de uma única notação (MOODY, 2009), essa é uma tarefa cognitivamente impossível. Isto é, não há como desenvolver uma linguagem ou notação "perfeita", que alcance indicadores máximos em todos requisitos de qualidade.

Como foi recomendado na avaliação da linguagem cidadã predecessora à esta, buscamos fundamentações em comunicação visual para atualizar a notação e construir a GERAL. Um dos elementos atualizados foram as setas de conexão entre os blocos, de setas grandes e com preenchimento vazio foram atualizadas para setas menores e preenchidas em preto, o próprio sequenciamento lógico da leitura ocidental já conduz a interpretação da informação na direção desejada (ENGELHARDT, 2002), sem necessidade de apelo gráfico às setas de ordenamento sequencial. O desenho ficou menor e melhor de ser percebido integralmente em interfaces.

\subsection{Método}

Permanecemos utilizando o catálogo de Engiel (2012) no método, desta vez atualizado com novos elementos, mais detalhado e fundamentado em cada decisão a ser tomada na tradução e transliteração. Com um passo específico dedicado para os princípios de Linguagem Cidadã.

Foram extraídos princípios operacionalizados em recomendações de Linguagem Cidadã dos guias já citados na Introdução, principalmente do guia brasileiro (BRASIL, 2016). Há uma etapa no passo-a-passo de tradução dedicado exclusivamente para adaptar o conteúdo à conformidade com a Linguagem Cidadã (CARVALHO, 2019).

Alguns exemplos de indicações são: não utilizar barras (“/”), sim "ou”; anunciar o que o usuário deve realizar no imperativo; evitar estrangeirismos e jargões; caso haja termos complexos, utilizar um elemento "glossário" e explicá-lo; não utilizar duplos negativos; dentre muitos outros. Esses elementos estão principalmente associados com os conteúdos textuais, enquanto as regras associadas com o conteúdo gráfico ficam expostas na sintaxe, no meta-modelo. Por exemplo, o tamanho da fonte é uma regra de sintaxe, o uso de ponto e vírgula é uma recomendação do método.

Há margem para o questionamento "por que não definir as recomendações de Linguagem Cidadã, assim como a sintaxe, como regras objetivas?". Porque uma linguagem cidadã é baseada 


\section{$17^{\circ}$ ERGODESIGN} \& USIHC 2019

PUC-Rio, 11 a 13 de dezembro

Rio de Janeiro, RJ, Brasil $17^{\circ}$ Ergodesign - Congresso Internacional de Ergonomia e Usabilidade de Interfaces Humano Tecnológica: Produto, Informações Ambientes Construídos e Transporte

$17^{\circ}$ USIHC - Congresso Internacional de Ergonomia e Usabilidade

de Interfaces Humano Computador

na efetividade subjetiva do público-alvo ao qual se intenciona comunicar (MÉXICO, 2004), então o tamanho da fonte é algo associado objetivamente com a qualidade isonômica da leitura, enquanto o uso, ou não, de mesóclise com o público-alvo que se pretende comunicar.

\subsection{BPMN pra GERAL}

Construído o framework, com suas fundamentações epistemológicas técnicas, precisávamos transparecê-lo. O interessado em traduzir seus modelos BPMN para GERAL não está interessado em ler referências de pesquisa científica ou meta-modelos complexos, ele quer instruções objetivas, simples e claras de como traduzir. Novamente utilizando a proposta de Linguagem Cidadã o framework foi sintetizado como um guia, nomeado "BPMN pra GERAL".

BPMN pra GERAL está disponível online ${ }^{3}$ e pode ser utilizado abertamente, assim como o trabalho de Carvalho (2019) que apresenta todas as suas fundamentações.

O guia foi utilizado e avaliado em um Estudo de Caso (YIN, 2018) na Biblioteca Central da UNIRIO, apresentando resultados positivos. As participantes do estudo expressaram claramente a percepção do esforço de comunicação do guia em ser simples, fácil e claro, demonstrando bom resultado do uso dos princípios importados. As Figuras 8 e 9 expõe um processo da biblioteca construído em BPMN e seu equivalente traduzido para GERAL, que utiliza todos seus elementos.

Figura 8: Processo da biblioteca construído em BPMN, empréstimo de material internacional (CARVALHO, 2019)

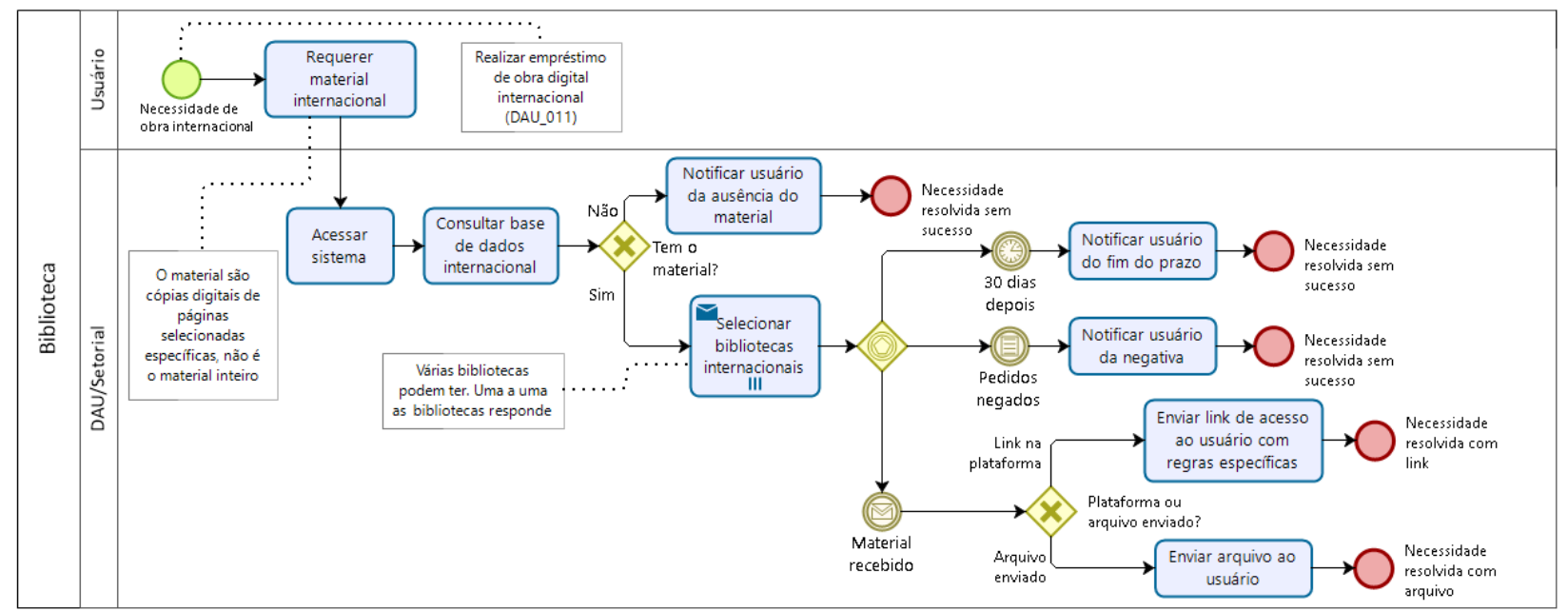

\footnotetext{
${ }^{3} \mathrm{https}: / /$ sites.google.com/view/bpmn-pra-geral
} 


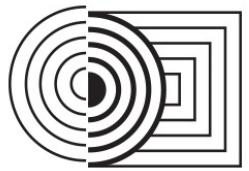

\section{$17^{\circ}$ ERGODESIGN} \& USIHC 2019

PUC-Rio, 11 a 13 de dezembro

Rio de Janeiro, RJ, Brasil

$17^{\circ}$ Ergodesign - Congresso Internacional de Ergonomia e Usabilidade de Interfaces Humano Tecnológica: Produto, Informações Ambientes Construídos e Transporte

$17^{\circ}$ USIHC - Congresso Internacional de Ergonomia e Usabilidade de Interfaces Humano Computador

Figura 9: Processo da biblioteca construído em GERAL, empréstimo de material internacional (CARVALHO, 2019)

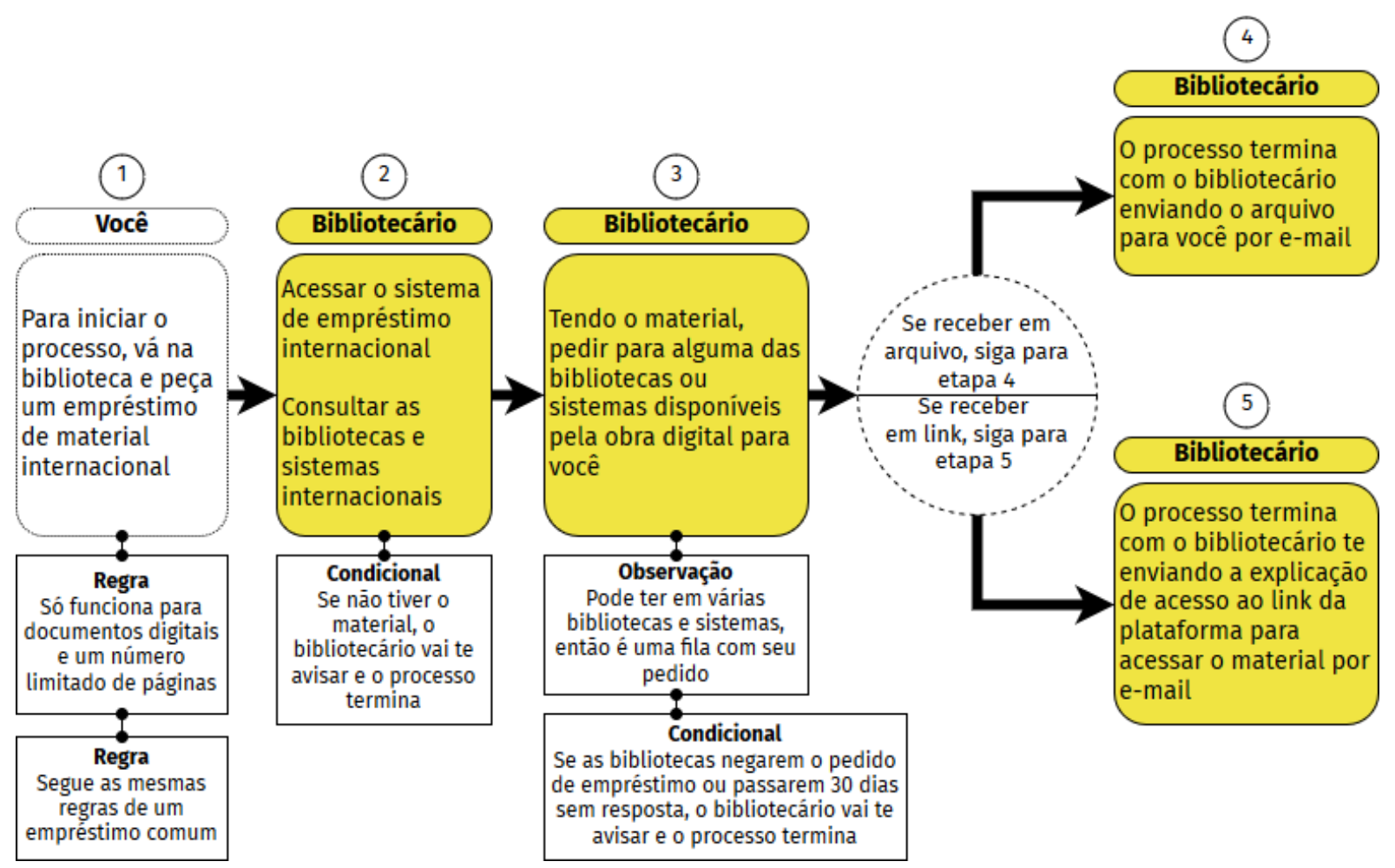

\section{CONCLUSÃO}

Conseguimos unir os princípios de Linguagem Cidadã, gráficos ou textuais, com fundamentos de melhor entendimento de modelos de processos de negócios. Construímos um artefato com requisitos funcionais e não-funcionais de Linguagem Cidadã. Requisitos funcionais, pois, indicamos, como regras ou recomendações, os princípios; não-funcionais pois o próprio artefato foi construído a partir de regras e recomendações dos mesmos princípios que indica.

Há como comunicar-se de forma simples, clara e intuitiva com o suporte de elementos gráficos, combinando pontos fortes das duas categorias, tanto textual como gráfica, como é evidenciado pela codificação dupla (MOODY, 2009).

O público-alvo, usuário do modelo GERAL, também não deve ser subestimado ou feito de trouxa, em caso de processos com pouquíssimos elementos ou informações complementares uma lista simples é preferível ao uso da GERAL, não há necessidade de sobrecarregar a comunicação com artifícios multidimensionais desnecessários.

Como compatível pela legislação (BRASIL, 2017), os modelos GERAL são adequados para comunicar informações processuais através de sistemas digitais. Podem ser baixados e, caso haja interesse das partes responsáveis, utilizados para auditar o processo a partir de apontamentos ou anotações.

Neste trabalho apresentamos uma pesquisa contendo uma iniciativa de transparência de processos, pouco abordada. Outros problemas e desafios de transparência, que podem ser resolvidos com apoio da Linguagem Cidadã, estão em aberto para serem abordados, avançando o estado democrático e habilitando um maior engajamento da sociedade. 


\section{REFERÊNCIAS BIBLIOGRÁFICAS}

Brasil. Lei n. 12.527 - Lei de Acesso à Informação (LAI), 2011. Disponível em: http://www.planalto.gov.br/ccivil_03/_ato2011-2014/2011/lei//12527.htm. Acesso em: 30/11/2019 Brasil. Lei n. 13.460. Disponível em: http://www.planalto.gov.br/ccivil_03/_Ato20152018/2017/Lei/L13460.htm. Acesso em: 30/11/2019

Brasil. Lei n. 13.709 - Lei Geral de Proteção de Dados Pessoais (LGPD), 2018b. Disponível em: http://www.planalto.gov.br/ccivil_03/_ato2015-2018/2018/lei/L13709.htm. Acesso em: 30/11/2019

Brasil. Ministério da Economia. GUIA DE LINGUAGEM. Fugindo do "burocratês": como facilitar o acesso do cidadão ao serviço público. 2016. Disponível em: http://www.planejamento.gov.br/cidadania-

digital/transformacao/arquivos/170627_Fugindo_burocrates_linguagem_cidada_PCD.pdf/view.

Acesso em: 30/11/2019

Brasil. Ministério do Planejamento, Desenvolvimento e Gestão. Estratégia de Governança Digital: Transformação Digital - cidadania e governo. Brasília, MP, 2018a. Disponível em: https://www.governodigital.gov.br/EGD/documentos/revisao-da-estrategia-de-governanca-

digital-2016-2019.pdf. Acesso em: 30/11/2019

Buttarelli, G. We need to talk about terms and conditions. European Data Protection Supervisor, 2019. Disponível em: https://edps.europa.eu/press-publications/press-news/blog/weneed-talk-about-terms-and-conditions_en. Acesso em: 30/11/2019

Cappelli, C. Uma Abordagem para Transparência em Processos Organizacionais Utilizando Aspectos. Tese de Doutorado, Pontifícia Universidade Católica do Rio de Janeiro (PUC-Rio), 2009.

Carvalho, L. P. Framework para Tradução de Modelos BPMN para uma Linguagem Cidadã de Processos: BPMN pra GERAL. Dissertação de mestrado, Universidade Federal do Estado do Rio de Janeiro (UNIRIO), 2019.

Carvalho, L. P., Cappelli, C., Santoro, F. Citizen Language: Color and Accessibility. doi: 10.5753/ihc.2018.4189 Porto Alegre, SBC, 2018.

Carvalho, L. P., Santoro, F, Cappelli, C. Um estudo sobre o entendimento de processos através de modelos com base no público alvo. II Escola Regional de Sistemas de Informação - Rio de Janeiro. Porto Alegre, SBC, 2015.

Carvalho, L. P., Santoro, F., Cappelli, C. Using a citizen language in public process models: The case study of a Brazilian university. Lect. Notes Comput. Sci., vol. 9831 LNCS, pp. 123134, 2016.

Clark, T., Sammut, P., Willans, J. Applied Metamodelling: A Foundation for Language Driven Development. ed. 3. arXiv:1505.00149, 2015.

Colômbia. Departamento Nacional de Planeación, GUÍA DE LENGUAJE CLARO PARA SERVIDORES PÚBLICOS DE COLOMBIA. 2015. Colômbia, D.F., 2015.

Controladoria Geral da União. INSTRUÇÃO NORMATIVA No 01 DA OUVIDORIA-GERAL DA UNIÃO DA CONTROLADORIA-GERAL DA UNIÃO, Manual para Ouvidores Federais”. 2015. Disponível em: http://www.ouvidorias.gov.br/ouvidorias/legislacao/instrucao-normativa/manualinstrucao-normativa.pdf. Acesso em: 30/11/2019

Dumas, M., La Rosa, M., Mendling, J. Reijers, H. A. Fundamentals of Business Process Management. Berlin, Springer Berlin Heidelberg, 2018.

Engelhardt, Y. The language of graphics. A framework for the analysis of syntax and meaning inn maps, charts and diagram. Tese de Doutorado, Universidade de Amsterdã, 2002. Engiel, P. Projetando o entendimento de modelos de processos de prestação de serviços 
públicos. Dissertação de mestrado, Universidade Federal do Estado do Rio de Janeiro (UNIRIO), 2012.

Franzoni, S. The journey of Citizen Language. Clarity, vol. 61, n. 8, pp. 27-28, 2009.

Genon, N., Heymans, P., Amyot, D. Analysing the Cognitive Effectiveness of the BPMN 2.0 Visual Notation. Software Language Engineering - Third International Conference, SLE 2010, pp. 377-396, 2011.

Holzner, B., Holzner, L. Transparency in global change: The vanguard of the open society. Pittsburgh, University of Pittsburgh Press, 2006.

Koene, A. Clifton, C. et al. A governance framework for algorithmic accountability and transparency. Panel for the Future of Science and Technology, doi: 10.2861/59990. Brussels, União Europeia, 2019.

Krogstie, J. Quality in business process modeling. Berlin, Springer, 2016.

Leite, J. C. S. P., Cappelli, C. Software Transparency. Bus. Inf. Syst. Eng., vol. 2, n. 3, pp. 127139, 2010.

Magrani, E. Entre dados e robôs: ética e privacidade na era da hiperconectividade. ed. 2. Porto Alegre, Arquipélago Editorial, 2019.

Meira, S. Princípios Fundamentais para Sistemas de Votação, Digitais ou Não. 2015. Disponível em: bit.ly/1T3RDlc. Acesso em: 30/11/2019

Moody, D. The "Physics" of Notations: Toward a Scientific Basis for Constructing Visual Notations in Software Engineering. IEEE Trans. Softw. Eng., vol. 35, n. 6, pp. 756-779, 2009. Mowat, C. Exploring meanings of plain language. Clarity, vol. 52, n. 13, pp. 42-46, 2004.

México. Secretaria de la Función Pública. Lenguaje Ciudadano, Un manual para quien escribe en la Administración Pública Federal. México, D.F., 2004.

Oliveira, R. Transformação Semiautomática de Processos Baseados em BPMN para Modelos Compreensíveis aos Cidadãos. Monografia, Universidade Federal do Estado do Rio de Janeiro (UNIRIO), 2018

Ottensooser, A., Fekete, A. et al. Making sense of business process descriptions: An experimental comparison of graphical and textual notations. J. Syst. Softw., vol. 85, n. 3, pp. 596-606, 2012.

PLAIN. Federal Plain Language Guidelines. 2011. Disponível em:https:/www.plainlanguage.gov/media/FederalPLGuidelines.pdf. Acesso em: 30/11/2019

Rover, T. Advogados exigem transparência em relação a processo eletrônico. Consultor Jurídico, 2014. Disponível em: https://www.conjur.com.br/2014-jul-12/advogados-exigemtransparencia-relacao-processo-eletronico. Acesso em: 30/11/2019

Stegner, B. 8 Ridiculous EULA Clauses You May Have Already Agreed To. MakeUseOf, 2019. Disponível em: https://www.makeuseof.com/tag/10-ridiculous-eula-clauses-agreed/. Acesso em: 30/11/2019

UE. Directorate-General for Translation (European Commission). How to write clearly. doi: 10.2782/29211, 2016.

Weske, M. Business process management: concepts, languages, architectures. Berlin, Springer, 2012.

Yin, R. K. Case Study Research and Applications. Design and Methods. ed. 6. EUA, SAGE, 2018 